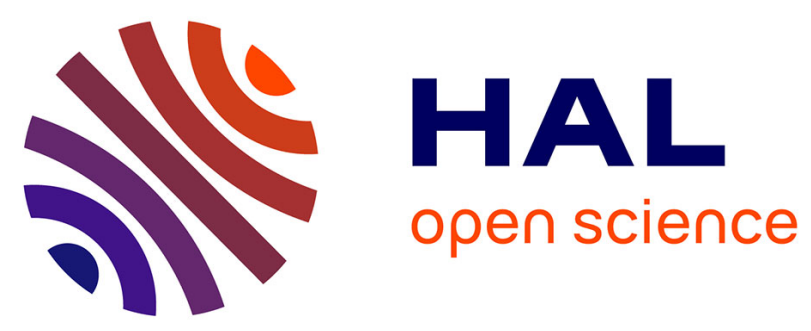

\title{
A core-shell phenomenon maintain the magnetocaloric properties of the ternary silicide Gd6Co1.67Si3 during water flux ageing
}

Madhu Chennabasappa, Bernard Chevalier, Michel Lahaye, Christine Labrugère, Olivier Toulemonde

\section{To cite this version:}

Madhu Chennabasappa, Bernard Chevalier, Michel Lahaye, Christine Labrugère, Olivier Toulemonde. A core-shell phenomenon maintain the magnetocaloric properties of the ternary silicide Gd6Co1.67Si3 during water flux ageing. Journal of Alloys and Compounds, 2014, 584, pp.34-40. 10.1016/j.jallcom.2013.08.211 . hal-00873638

\section{HAL Id: hal-00873638 https://hal.science/hal-00873638}

Submitted on 1 Jun 2016

HAL is a multi-disciplinary open access archive for the deposit and dissemination of scientific research documents, whether they are published or not. The documents may come from teaching and research institutions in France or abroad, or from public or private research centers.
L'archive ouverte pluridisciplinaire HAL, est destinée au dépôt et à la diffusion de documents scientifiques de niveau recherche, publiés ou non, émanant des établissements d'enseignement et de recherche français ou étrangers, des laboratoires publics ou privés. 


\title{
A core-shell phenomenon maintain the magnetocaloric properties of the ternary silicide
}

\section{$\mathrm{Gd}_{6} \mathrm{CO}_{1.67} \mathrm{Si}_{3}$ during water flux ageing}

Chennabasappa M., Chevalier B., Lahaye M., Labrugère C., Toulemonde O.

\begin{abstract}
:
Ageing effect phenomenon is artificially stimulated on room temperature magnetocaloric material $\mathrm{Gd}_{6} \mathrm{Co}_{1.67} \mathrm{Si}_{3}$ by using constant flux of water up to time interval of 3 months. A core-shell model of oxide layer formation $\left(\mathrm{SiO}_{x}-\mathrm{Gd}_{2} \mathrm{O}_{3}\right)$ on surface of $\mathrm{Gd}_{6} \mathrm{CO}_{1.67} \mathrm{Si}_{3}$ due to corrosion is justified using spontaneous single metal electrochemical reactions. The model is first proposed by a detailed microstructure study using Electron Probe Micro-Analysis, X-ray diffraction experiments on the aged slab revealing $\mathrm{Gd}_{2} \mathrm{O}_{3}$ phase and elemental depth profile analysis against time by Auger spectroscopy. It is further supported by surface chemical bonding study using X-ray Photoelectron Spectroscopy (XPS) concentrated on Si2p and 01s spectra. It is finally demonstrated that the room temperature bulk magnetocaloric performances of the material are not affected even under formation of corroded layer at the micron level scale. The $\mathrm{Gd}_{2} \mathrm{O}_{3}$ shell certainly acts as a passivation layer.
\end{abstract}

\section{Introduction}

In recent years there was great quest for search of magnetocaloric materials for applications in ambient temperature cooling applications [1] and [2]. They are preferred over conventional gas refrigerators as they are expected to be environmentally friendly. Magnetocaloric materials have been successfully tested in cryogenic refrigeration and lot of prototypes has been proposed for near room temperature domestic applications [3]. It is worth to investigate the interaction of working fluid, the so called ageing effect, of these materials in order to know the reliability and improve their performance with time [4], [5] and [6]. There exist very few such investigations to date. The first one was by Canepa et al. who conducted detailed ageing under influence of different refrigerant fluids (air, water, ethylene glycol, alcohol propylic and Freon 245 ) on $\mathrm{Gd}, \mathrm{Gd}_{5} \mathrm{Si}_{1.9} \mathrm{Ge}_{2.1}$ and $\mathrm{Gd}_{75} \mathrm{Cd}_{25}[4]$. They reported that $\mathrm{Gd}$ and $\mathrm{Gd}$-based intermetallics undergo corrosion and erosion which eventually decrease their performance with time of exposure to the fluid. Effort to protect the surface from the corrosion by gold coating also failed as after 6 month the corrosion is much enhanced even compared to the uncoated sample. They put forward concept of galvanic corrosion and explained formation of $\mathrm{Gd}(\mathrm{OH})_{3}$ on the surface of the material. Interestingly, they observe no change in the magnetocaloric performance of their material until 100 days. More recently Min Zhang et al. demonstrated a rapid corrosion followed by degradation of the compound $\mathrm{La}\left(\mathrm{Fe}_{0.94} \mathrm{CO}_{0.06}\right)_{11.7} \mathrm{Si}_{1.3}$ even by just placing it in distilled water for 15 days [5]. They conclude the final product on surface due to corrosion to be $\mathrm{La}_{2} \mathrm{O}_{3}, \gamma-\mathrm{Fe}(\mathrm{OOH}), \mathrm{Co}(\mathrm{OH})_{2}$ and $\mathrm{H}_{2} \mathrm{SiO}_{3}$. They also propose an electrochemical preferential corrosion that results in decrease of the weight. In contrast to previous study of $\mathrm{Gd}$-based compounds, they observe a drastic decrease in maximum magnetic entropy for the La-based compound whereas such materials are still subject to extended studies [7]. In most of the prototypes and reports on ageing, distilled water has been highlighted to be better heat transport fluid comparing its physical properties with other heat transfer fluids, so we choose distilled water as working fluid in our experiments [8]. Furthermore, the use of pure distilled water as heat exchange medium without adding any antioxidant was done on purpose. Indeed, this choice allows us to carefully study the chemical effects of the water on the material to be able to control them in the future.

$\mathrm{Gd}_{6} \mathrm{Co}_{1.67} \mathrm{Si}_{3}$ material was first reported with detailed structural, magnetic and more recently for its room temperature magnetocaloric effect (MCE) by Gaudin et al. [9] and [10]. In brief, $\mathrm{Gd}_{6} \mathrm{Co}_{1.67} \mathrm{Si}_{3}$ is one of the most thermodynamically stable composition derived from ternary phase diagram of $\mathrm{Gd}-\mathrm{Co}-\mathrm{Si}$. It crystallizes in hexagonal symmetry and adopts $\mathrm{Ce}_{6} \mathrm{Ni}_{1.67} \mathrm{Si}_{3}$-type structure $\left(P 6_{3} / m\right.$ space group). $\mathrm{Gd}_{6} \mathrm{Co}_{1.67} \mathrm{Si}_{3}$ exhibit second order ferromagnetic to paramagnetic 
transition at $T_{\mathrm{C}}=294 \mathrm{~K}$ and this is the unique composition in this phase diagram to exhibit $T_{\mathrm{C}}$ around room temperature. Magnetic entropy change $(\Delta S=2.9 \mathrm{~J} / \mathrm{K} \mathrm{kg} ; \Delta H=2 T)$ and adiabatic temperature $(\Delta T=3 \mathrm{~K} ; \Delta H=2 \mathrm{~T}$ ) change of this material are also quite interesting considering the fact that $\mathrm{Gd}_{6} \mathrm{Co}_{1.67} \mathrm{Si}_{3}$ contains only 56 at.\% of $\mathrm{Gd}$. Similar ternary silicides based on other rare earth [11] and especially his particular composition has been successfully reproduced in terms of purity, magnetization and observed magnetocaloric effect by few other groups [12] and [13]. Considering all these facts, we decide to study its ageing effect. In this report we present $\mathrm{X}$-ray diffraction, detailed microstructure changes, surface analysis and magnetization results during ageing of $\mathrm{Gd}_{6} \mathrm{Co}_{1.67} \mathrm{Si}_{3}$ in flux of distilled water.

\section{Experimental}

$\mathrm{Gd}_{6} \mathrm{Co}_{1.67} \mathrm{Si}_{3}$ was prepared from high pure elements $\mathrm{Gd}(99 \%)$, $\mathrm{Co}(99.9 \%)$ and $\mathrm{Si}(99.9 \%)$ by arc melting them in pure argon atmosphere. Arc melting was repeated two more time by reversing the ingot to ensure homogeneity. Further as prepared ingots were sealed in evacuated quartz tube and annealed at $800^{\circ} \mathrm{C}$ for month. Later, thin slabs of approximately $1.5-$ $2 \mathrm{~mm}$ thinkness, $8 \mathrm{~mm}$ length and $4 \mathrm{~mm}$ wide were cut from annealed sample to perform ageing. These slabs were well polished to ensure smooth surface and then exposed for ageing.

For ageing, $\mathrm{Gd}_{6} \mathrm{Co}_{1.67} \mathrm{Si}_{3}$ was treated with continuous constant flux of water, we use small aging set-up to artificially stimulate the heat transfer and this is conceptually similar to the one reported [4]. Water was pumped from the reservoir into sample chamber with constant flux with the aid of aquarium pump (EHEIM compact 300). The exposed slabs were periodically (every month) analyzed to well understand the effect of ageing. After exposure of the sample to flux of heat transport fluid for specific period of time ( 1 month, 2 months, etc.), the drying samples procedure is the following: the samples were removed from cell and placed on the top of a paper tissue to drain the excess water. Later the samples were allowed to stand by for overnight at room temperature. Any heat treatment to dry water was avoided.

Phase purity of as cast and annealed ingot was confirmed from powder X-ray diffraction performed on Philips 1050 diffractometer. Magnetic measurements were performed on MPMS SQUID instrument (Quantum Design, USA). Elemental analysis was performed on Electron Probe Micro Analyzer (EPMA) (CAMECA SX 100 - Bruker AXS) equipped with 3 different spectroscopes WDS (Wavelength-Dispersive Spectroscopy), EDS (Energy-Dispersive Spectroscopy) and SDDD (Silicon Drift Detector). Depth profile analysis was carried out on Auger electron spectroscopy (VG microlab 310F) equipped with sputter ion gun. ICP-OES (Induced Couple Plasma - Optical Emission Spectroscopy) measurements were performed on Varian 720-ES. X-ray photoelectron spectroscopy (XPS) was performed using VG Scientific 220 i-XL ESCALAB spectrometer with a monochromatized Al Ka source $(h v=14866 \mathrm{eV})$ at $70 \mathrm{~W}$ under pressure of $10^{-7} \mathrm{~Pa}$ in the chamber. The spot size is about $180 \mu \mathrm{m}$ in diameter. The full spectra $(0-1350 \mathrm{eV})$ were obtained with constant pass energy of $150 \mathrm{eV}$ and high resolution spectra at constant pass energy of $40 \mathrm{eV}$.

\section{Results and discussion}

\subsection{Structural studies}

$\mathrm{X}$-ray diffraction (XRD) on powder of the annealed sample revealed phase purity. We were able to refine the structure in hexagonal $P 6_{3} / m$ space group with " $\mathrm{Ce}_{6} \mathrm{Ni}_{1.67} \mathrm{Si}_{3}$ " type structure as reported in the literature. [10]Fig. 1 shows the $\mathrm{X}$-ray diffraction on thin slabs of starting or aged samples. They exhibit broader X-ray patterns which makes the data difficult to perform qualitative analysis. However, we are able to profile match them and the results are displayed in Fig. 1 (a) and (b). As prepared sample was profile matched with the proposed $P 6_{3} / m$ space group $(a=b=11.838(1) \AA, c=4.161$ (3) $\AA$, $\alpha=\beta=90^{\circ}$ and $\gamma=120^{\circ}$ ). For aged samples we could only obtain reasonable profile fit after taking into account a $\mathrm{Gd}_{2} \mathrm{O}_{3}$ $\left(\right.$ I $a-3 ; a=b=c=10.797(1) \AA$ and $\left.\alpha=b=\gamma=90^{\circ}\right)$ [ICSD \#41270] secondary phase. Interestingly, we highlight a corrosion phenomenon resulting in the formation of $\mathrm{Gd}_{2} \mathrm{O}_{3}$ oxide somewhat contrary to the formation of $\mathrm{Gd}(\mathrm{OH})_{3}$ hydroxides in case of $\mathrm{Gd}_{5} \mathrm{Si}_{1.9} \mathrm{Ge}_{2.1}, \mathrm{Gd}_{75} \mathrm{Cd}_{25}$, Gd-rich materials [4]. Such results will be discussed in section 3.3.

\subsection{Microstructural studies}

\subsubsection{Electron probe microscope studies}


To well understand the surface morphology and to check the distribution on overall surface compositional changes during ageing we have performed EPMA, since only $\mathrm{Gd}_{2} \mathrm{O}_{3}$ is observed on XRD. Backscattering image of starting and 3 month aged sample shows clear change in morphology due to water flux and/or corrosion reactions, with smoother surface for starting (Fig. 2 a) and more rough surface morphology for aged sample (Fig. 2 b). We perform elemental analysis following atomic \% mapping on starting slab. Despite some rich siliceous domains homogeneous elemental distribution is observed on entire surface (Fig. 2 c). The atomic mapping confirmed nominal composition $\mathrm{Gd}_{6} \mathrm{Co}_{1.67} \mathrm{Si}_{3}$ all along scanned area (to note, the random and constant oxygen signal observed is mainly due to exposure of sample surface to atmosphere). While similar elemental mapping on 3 months aged sample display heterogeneous distributions of elements along with higher and widely distributed oxygen signal (Fig. 2 d). To study the starting effect of ageing on microstructure and elemental distribution, more detailed experiments on 2 months aged sample were performed and the results are tabulated in Fig. $3(a-f)$. In some portion a valley like structure is highlighted in red on Fig. 3 (a), this suggest an erosion process around grain boundary due to interaction of flux. Fig. 3 (c-f) displays elemental mapping for all the constituent elements along with that of oxygen within the same area. One can notice that the elemental distribution is heterogeneous unlike starting composition, there are $\mathrm{Gd}_{6} \mathrm{Co}_{1.67} \mathrm{Si}_{3}$ phase poor region corresponding to the oxygen rich region. Atomic \% mapping on selected region (containing both oxygen rich and oxygen poor region) was performed and results are displayed in Fig. $3(b)$. This mapping confirms that oxygen poor region corresponds to the original composition of $\mathrm{Gd}_{6} \mathrm{Co}_{1.67} \mathrm{Si}_{3}$ and with careful analysis one can notice that oxygenated region is rich in $\mathrm{Gd}$ content compared with $\mathrm{Si}$ or Co. In most of these high oxygen regions the atomic percentage of $\mathrm{Gd}$ corresponds approximately to 25 and that of oxygen to 66 . This is in agreement with our XRD pattern matching with $\mathrm{Gd}_{2} \mathrm{O}_{3}$ crystallographic phase.

\subsubsection{Depth profile analysis by auger}

We have further performed depth profile analysis using Auger spectroscopy. It will address whether the oxygen layer is constrained to the surface or is penetrated into the sample with time. Auger spectroscopy is equipped with ion sputtering chamber; sputtering facilitates controlled etching of surface and Auger spectroscopy help in elemental analysis. The surface of as prepared sample shows surface oxidation up to $75 \mathrm{~nm}$ likely due to atmosphere exposure of sample (Fig. 4(a)) as already seen on the previous section. However, for 2 months ageing this depth increase to around $800 \mathrm{~nm}$ and after 3 months exposure the depth of oxygen is around $1200 \mathrm{~nm}$ (Fig. 4(b) and (c)). From these studies we propose that water flux results in formation of oxide layer, thickness of which increase with time of exposure. If one observe carefully on these histograms of aged sample (for example Fig. 4(b)), it can be noticed that on top layer (say up to $100 \mathrm{~nm}$ ) there is only Si signal along with that of oxygen. After which $\mathrm{Gd}$ signal increase along with decrease in Si signal and still there is no contribution in Co signal. Only after $600 \mathrm{~nm}$ thickness we find nominal composition of starting material. Similar results were observed on different spots of the 2 months aged material. Based on these observations we propose that ageing leads to oxide formation on surface of the material which takes the form of "core-shell": the outer most layer to be $\mathrm{SiO}_{x}$, followed by $\mathrm{Gd}_{2} \mathrm{O}_{3}$ as seen on XRD and the core to be the original composition of the material (Fig. 4(d)).

\subsection{Spontaneous electrochemical reaction}

As just introduced on the previous paragraph, flux of the working fluid introduces competition between corrosion and erosion phenomena. The oxidation of the surface can be explained based on the single metal corrosion phenomenon because of bubble $\mathrm{O}_{2}$ which becomes the cathode, into the water introduced on the ageing set-up. The tendency for a reaction to occur follows the order of the electrochemical series tabulated in Table 1. Based on it, the overall corrosion can be suggested as follows. At initial stage cobalt metal on $\mathrm{Gd}_{6} \mathrm{Co}_{1.67} \mathrm{Si}_{3}$ slab is corroded following equation $\mathrm{O}_{2(\mathrm{~g})}+2$ $\mathrm{H}_{2} \mathrm{O}+2 \mathrm{Co}^{2+} \rightarrow 4 \mathrm{OH}^{-}+2 \mathrm{Co}_{(\mathrm{aq})}^{2+} \mathrm{Co}(\mathrm{aq}) 2+(7)$ that will result in $\mathrm{Co}_{\text {aq }}^{2+} \mathrm{Coaq} 2+$ within water explaining the lack of cobalt on the deep profile analysis. Once one can point out that $\mathrm{Si}$ can be corroded at different level of oxidation state. It follows the successive change in redox potential required for the spontaneous reaction from $\mathrm{Si}$ "l-O $\left(E^{0}=-0.8 \mathrm{eV}\right) \rightarrow \mathrm{Si}^{\mathrm{iV}} \mathrm{O}_{2} \mathrm{SilVO}_{2}$ $\left(E^{0}=-0.9 \mathrm{eV}\right) \rightarrow \mathrm{Si}^{j \mathrm{~V}} \mathrm{O}_{3}^{2-}$ O32- $\left(E^{0}=-1.7 \mathrm{eV}\right)$. Such stepped edges of corrosion can explain the time dependent $\mathrm{SiO}_{x}$ thickness along the total thickness of corroded layer and should introduced a Si heterogeneous oxidation state on the $\mathrm{SiO}_{x}$ sub-layer. Finally, the reaction $3 \mathrm{O}_{2(\mathrm{~g})}+2 \mathrm{H}_{2} \mathrm{O}+4 \mathrm{Gd} \rightarrow 12 \mathrm{OH}^{-}+4 \mathrm{Gd}^{3+}{ }_{\text {(aq) }}$ (8) will occur. Our coupled XRD and EMPA analyses unambiguously suggest that the expected $\mathrm{Gd}_{\mathrm{aq}}^{3+} \mathrm{Gdaq} 3+$ cation is replaced by the oxide $\mathrm{Gd}_{2} \mathrm{O}_{3}$ more stable than the hydroxide $\mathrm{Gd}(\mathrm{OH})_{3}$ within our experimental conditions resulting in a passivation surface around the $\mathrm{Gd}_{6} \mathrm{Co}_{1.67} \mathrm{Si}_{3}$ slab 
material. Such chemical nature change of $\mathrm{Gd}^{3+}$ cation (from $\mathrm{Gd}_{\mathrm{aq}}^{3+} \mathrm{Gdaq} 3+$ to Oxide $\mathrm{Gd}_{\mathrm{s}}^{3+} \mathrm{Gds} 3+$ or hydroxyde $\mathrm{Gd}_{s}^{3+}$ Gds3+) is known to be in relation with acidity decreases of the solvant when Pourbaix diagram is plotted. To definitely conclude on the single metal corrosion phenomenon, one must demonstrate the presence of $\mathrm{Gd}_{\mathrm{aq}}^{3+} \mathrm{Gdaq}_{3+} \mathrm{and} \mathrm{SiO}_{3(\mathrm{aq})}^{2-}$ $\mathrm{SiO} 3(\mathrm{aq}) 2$ - within the water flux and a distribution of silicium oxidation state at the surface of the slab.

\subsection{Chemical analysis}

\subsubsection{ICP analysis}

From above mentioned spectroscopic studies (section 3.2) we never come across the state of cobalt on the surface of the sample until we observe nominal composition, there are two possibilities: (i) Co dissipates into the material (Co vacancies) but this is not possible as the maximum Co occupancy is limited to 1.67 for this particular composition [9] and [10]. The other possibility, (ii) $\mathrm{Co}$ is corroded due to the $\mathrm{O}_{2}$ within the water flux as just suggested equation (7). To insure the possibility of corrosion of the material we performed ICP-OES analysis of the fluid from the ageing cell. Three trials of fluids from the sample chamber were withdrawn to perform the ICP study. In all of these three solutions we find higher content of cobalt ( $\mathrm{Co} / \mathrm{Gd}=1.22$ as compared to starting $\mathrm{Co} / \mathrm{Gd}=0.28$ ) in the fluid, this gives better picture of the overall effect of ageing. Interestingly, we also extract $\mathrm{Si} / \mathrm{Gd}=0.86$ against the starting $\mathrm{Si} / \mathrm{Gd}=0.5$ which suggest that $\mathrm{Si}$ is also

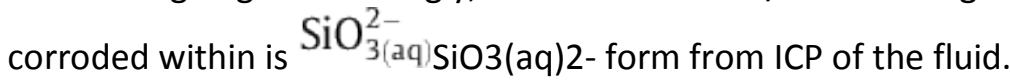

\subsubsection{Chemical state by XPS}

To know the specific metal-oxide species that is formed on surface, especially the $\mathrm{Si}-\mathrm{O}$ bonding and to corroborate it with a stepped corrosion proposed for silicon, detailed X-ray Photoelectron Spectroscopy (XPS) measurements were performed. Our analysis is based on the phenomenological rule allowing the prediction of relative binding energy position depending on the degree of ionic and/or covalent character in the bonding of metal oxides. For example, from $\mathrm{ZrSiO}_{4}$ to $\mathrm{SiO}_{2}$ materials, an increase of both the $\mathrm{O} 1 \mathrm{~s}(531.3 \mathrm{eV} \rightarrow 532.7 \mathrm{eV})$ and $\mathrm{Si} 2 p(101.8 \mathrm{eV} \rightarrow 103.15 \mathrm{eV})$ features is seen in relation with the increase of the ionic character of the Si-O bonding [13] XPS were performed on unscratched and scratched surface (Fig. 5 (a) and (b)) to probe the first corroded layers.

On the unscratched slab, in agreement with Auger measurements we do not observe any trace of Co and Gd on the surface. We only observe Si2p and O1s spectra which are treated and discussed in detail as follows. Fitting of Si2p was made taking into account all possible Si-oxidation states expected: (i) $\mathrm{Si}^{0}$ oxidation states from pristine $\mathrm{Gd}_{6} \mathrm{Co}_{1.67} \mathrm{Si}_{3}$ exhibiting $\mathrm{Si} 2 p$ at $98.8 \mathrm{eV}$ (ii) $\mathrm{Si}^{+4}$ from $102.5 \mathrm{eV}$ [14] on amorphous material to $103.15 \mathrm{eV}$ on crystalline one's for $\mathrm{SiO}_{2}$ bonding. [15] For intermediate oxidation of $\mathrm{Si}^{+2}$ a signature peak appears at $100.5 \mathrm{eV}$ i.e. at interval of $1.7 \mathrm{eV}$ with respect to $\mathrm{Si}^{0}$ position. [16] and [17] We were able to fit the Si2p spectra with three spin-orbit doublets centered at $101.7 \mathrm{eV}$ (19\%), $102.7 \mathrm{eV}(56 \%)$ and $104.4 \mathrm{eV}(25 \%)$ with theirs corresponding areas. We suggest that these features are due to Si$\mathrm{C}-\mathrm{O}$ bonding since we do not scratch the surface, amorphous more covalent $\mathrm{SiO}_{2}$ bonding and more ionic $\mathrm{SiO}_{3}^{2-} \mathrm{SiO}_{2}-$ bonding respectively. Further we fit $\mathrm{O} 1 \mathrm{~s}$ as shown in Fig. 5 (b) considering $\mathrm{O} 1 \mathrm{~s}$ peak at $530.5 \mathrm{eV}$ for $\mathrm{Gd}-\mathrm{O}$ bonding from atmosphere exposure as seen on $\mathrm{Gd}$ metal slab and pristine $\mathrm{Gd}_{6} \mathrm{Co}_{1.67} \mathrm{Si}_{3}$ slab, and at $531.7 \mathrm{eV}$ [15] on amorphous material and $533 \mathrm{eV}$ on crystalline one's [14] for $\mathrm{SiO}_{2}$ bonding. In our case we observe 4 peaks at energies $530.8 \mathrm{eV}(13 \%), 532.2 \mathrm{eV}$ $(30 \%), 533.2 \mathrm{eV}(34 \%)$ and $534.3 \mathrm{eV}(23 \%)$ with their respective area. Once again, since the surface was not scratched, we suggest the feature at $532.2 \mathrm{eV}$ originated from $\mathrm{Si}-\mathrm{C}-\mathrm{O}$ bonding due to air exposure. If the feature at $530.8 \mathrm{eV}$ is related to $\mathrm{Si}-\mathrm{O}-\mathrm{Gd}$ bonding interface, we suggest the features at $533.2 \mathrm{eV}$ and $534.3 \mathrm{eV}$ correlated to the more covalent $\mathrm{SiO}_{2}$ bonding and more ionic $\mathrm{SiO}_{3}^{2-} \mathrm{SiO} 2$ - bonding respectively. The main contributions of the both $\mathrm{Si} 2 \mathrm{p}$ and $01 \mathrm{~s}$ spectra would be due to $\mathrm{Si}^{4+} \mathrm{O}_{x}$-type bonding with a mixture of covalent and ionic character in between $\mathrm{SiO}_{2}$ and $\mathrm{SiO}_{3}^{2-} \mathrm{SiO}_{2}-$ species. However, to definitively support the stepped spontaneous reaction from $\mathrm{Si}^{\prime \prime}-\mathrm{O}\left(E^{0}=-0.8 \mathrm{eV}\right) \rightarrow \mathrm{Si}^{\mathrm{iV}} \mathrm{O}_{2}$ $\left(E^{0}=-0.9 \mathrm{eV}\right) \rightarrow \mathrm{Sil}^{\mathrm{il}} \mathrm{O}_{3}^{2-} \mathrm{O} 32-\left(E^{0}=-1.7 \mathrm{eV}\right)$ at the slab/water interface, we should see a decrease of the more ionic species after scratching the surface in situ. 
Spectra resulting from scratched surface show extra contributions of oxidized Gd peaks but still we do not observe any $\mathrm{Co}$. These observations make us believe we are still in the corroded region far from the core consisting original $\mathrm{Gd}_{6} \mathrm{Co}_{1.67} \mathrm{Si}_{3}$. As previously, we focus our study on the Si2p and O1s spectra ( Fig. 5(c) and (d)). The Si2p was also fit by using 3 spinorbit doublets with the main peaks centered at $101.6 \mathrm{eV}(16 \%), 102.7 \mathrm{eV}(70 \%)$ and $103.9 \mathrm{eV}(14 \%)$ and $01 \mathrm{~s}$ peak was now fitted using 5 peaks centered at $529.9 \mathrm{eV}(7 \%), 530.9 \mathrm{eV}(10 \%), 532 \mathrm{eV}(30 \%), 533 \mathrm{eV}(45 \%)$ and $534 \mathrm{eV}(8 \%$.) [18] The new $01 s$ peak around $530 \mathrm{eV}$ is likely due to $\mathrm{Gd}-\mathrm{O}$ type bonding in relation with the oxidation observed on the top of a metal Gd slab exposed to air. Interestingly, the relative areas of the main features at $102.8 \mathrm{eV}$ on Si2 $p$ and $533.1 \mathrm{eV}$ on $01 \mathrm{~s}$ spectra resulting from $\mathrm{SiO}_{2}$ bonding are unambiguously enhanced with the scrapping procedure eliminating the top corroded layers $\mathrm{Si}-\mathrm{O}-\mathrm{C}$ and $\mathrm{SiO}_{3}^{2-} \mathrm{SiO} 32-$ bonding-type. This tendency in the distribution of $\mathrm{SiO}_{3}^{2-} \mathrm{SiO}_{2}-/ \mathrm{SiO}_{2}$ on the top layer of the shell is definitively link with our hypothesis of time dependent variation of $\mathrm{SiO}_{x}$ layer based on electrochemical corrosion. Because the difference on the standard reduction potentials between $\mathrm{SiO} / \mathrm{Si}$ and $\mathrm{SiO}_{2} / \mathrm{SiO}$ couples is low, the SiO oxide is not stable as further supported by our XPS study.

In conclusion, with time of exposure to water flux, the cobalt is first oxidized to $\mathrm{Co}_{\text {aq }}^{2+} \mathrm{Coaq2+}$ allowing its dissolve to the water and resulting in a "pristine $\mathrm{Gd}_{6} \mathrm{CO}_{1.67} \mathrm{Si}_{3}$ core" / " $\mathrm{Gd}_{2} \mathrm{O}_{3}-\mathrm{SiO}_{x}$ shell". The so formed oxide-corroded layer of silicon wears out when $\mathrm{SiO}_{3}^{2-}$ SiO32- ionic species is formed exposing gadolinium at surface of sample. Interestingly, $\mathrm{Gd}_{2} \mathrm{O}_{3}$ would act as a passivation layer that slows down the erosion. This step is reflected as decrease in $\mathrm{SiO}_{x}$ sub layer thickness in parallel to an increase of $\mathrm{Gd}_{2} \mathrm{O}_{3}$ thickness with time and supported by our XPS studies.

\subsection{Physical properties}

Since the chemical (corrosion) and mechanical (erosion) actions of the water flux into Gd6Co1.67Si3 slab material are highlighted and understood, we present the central part of our study i.e. the MCE performance of the material before and after ageing by evaluating the TC, isothermal curves and magnetic entropy change. Fig. 6(a) compares the magnetization as function of temperature for starting and 3 month aged samples which confirm no change in the abrupt jump from paramagnetic to ferromagnetic (TC) after ageing. The entropy changes for these two samples are calculated from the isothermal curves obtained around the magnetic transition and results are shown in Fig. 6(b). After 3 month of ageing and with oxide layer of around $1.2 \mu \mathrm{m}$, we observe no change in TC or entropy change. This result is highly promising compared to La-Fe-Co-Si system which shows considerable decrease in total entropy because of the paramagnetic character of the $\mathrm{Gd} 2 \mathrm{O} 3$ passivation layers. The aging phenomenon does not change the total spin density of the core/shell material compare to these of the pristine one. It is also worth to note our compounds undergo much less mechanical damage in the present ageing conditions for which we do not control the water flow. So we propose that Gd-based intermetallics are better choice of materials for the practical implementation in household applications compared to La-Fe-Co-Si system. Gd-based intermetallics could also be alternate to perovskite related manganites [19] for which their corrosion resistance is underway.

\section{Conclusions}

We have presented detailed chemical and microstructural analysis of ageing process in constant flux of water on the ternary silicide $\mathrm{Gd}_{6} \mathrm{CO}_{1.67} \mathrm{Si}_{3}$. Core-shell model of formation of $\mathrm{SiO}_{x}-\mathrm{Gd}_{2} \mathrm{O}_{3}$ on surface of $\mathrm{Gd}_{6} \mathrm{Co}_{1.67} \mathrm{Si}_{3}$ is proposed based on XRD, EMPA and depth profile by Auger spectroscopy analysis. The cobalt on surface was found to be corroded to $\mathrm{Co}_{\mathrm{aq}}^{2+}$ Coaq2+ and dissolve to the water as supported by ICP and XPS analysis. Further, XPS confirms the oxide at top surface to be mainly $\mathrm{SiO}_{x}$ without much trace of hydroxide but with a time dependant thickness related to spontaneous single metal corrosion phenomenon involving the two couple $\mathrm{SiO}_{2} / \mathrm{SiO}$ and $\mathrm{SiO}_{3}^{2-} / \mathrm{SiO}_{2} \mathrm{SiO} 32-/ \mathrm{SiO} 2$ and resulting in $\mathrm{SiO}_{3}^{2-} \mathrm{SiO}_{2-}$ ionic species dissolution at the end of the oxidation process. That is why a final $\mathrm{Gd}_{6} \mathrm{Co}_{1.67} \mathrm{Si}_{3} / \mathrm{Gd}_{2} \mathrm{O}_{3}$ interface is suggested. Remarkably the bulk magnetocaloric effect is unaltered even with this micron length oxide layer on surface because of the paramagnetic $\mathrm{Gd}_{2} \mathrm{O}_{3}$ passivation layer.

\section{Acknowledgements}


Authors like to acknowledge Dr Michaël POLLET, Dr Etienne GAUDIN for fruitful discussions. Eric Lebraud for XRD, Olivier Nguyen for his assistance in magnetic measurements, Laetetia Etienne for ICP analysis. Author MC acknowledge Université de Bordeaux1 for his PhD fellowship. This work was supported by "le Conseil Régional d'Aquitaine", the ANR (Agence Nationale pour la Recherche) through the research project "MAGCOOL" (ANR_2010_STKE_008).

\section{Reference}

1. O. Tegus, E. Brück, K.H.J. Buschow, F.R. de Boer. Nature, 415 (2002), p. 150.

2. K.A. GschneidnerJr, V.K. Pecharsky, A.O. Tsokol. Rep Prog Phys, 68 (2005), p. 1479.

3. L.T. Kuhn, N. Pryds, C.R.H. Bahl, A. Smith. J Phys Conf Ser, 303 (2011), p. 0120.

4. F. Canepa, S. Cirafici, M. Napoletano, M.R. Cimberle, L. Tagliafico, F. Scarpa. J Phys D Appl Phys, 41 (2008), p. 155004.

5. M. Zhang, Y. Long, R. Ye, Y. Chang. J Alloys Comp, 509 (2011), p. 3627.

6. M. Balli, O. Sari, L. Zamni, C. Mahmed, J. Forchelet. Mater Sci Eng B, 177 (2012), p. 629.

7. L. Lyubina, U. Hannemann, L.F. Cohen, M.P. Ryan. Adv Energy Mater, 2 (2012), p. 1323.

8. A. Smith, C.R.H. Bahl, R. Bjørk, K. Engelbrecht, K.K. Nielsen, N. Pryds. Adv Energy Mater, 2 (2012), p. 1288.

9. E. Gaudin, S. Tencé, F. Weill, J.R. Fernandez, B. Chevalier. Chem Mater, 20 (2008), p. 2972.

10. E. Gaudin, F. Weill, B. Chevalier. Z Naturforsch, 61b (2006), p. 825.

11. B. Chevalier, E. Gaudin, F. Weill. J Alloys Comp, 442 (2007), p. 149.

12. S.N. Jammalamadaka, N. Mohapatra, S.D. Das, K.K. Iyer, E.V. Sampathkumaran. J Phys Condens Matter, 20 (2008), p. 425204.

13. S. Jun, L. Yang-Xian, D. Qiao-Yan, W. Fang, S. Ji-Rong. Chinese Phys B, 17 (2008), p. 2268.

14. M.J. Guittet, J.P. Crocombette, M. Gautier-Soyer. Phys Rev B, 63 (2001), p. 125117.

15. D. Löffler, J.J. Uhlrich, M. Baron, B. Yang, X. Yu, L. Lichtenstein, L. Heinke, C. Büchner, M. Heyde, S. Shaikhutdinov, H.-J. Freund, R. Włodarczyk, M. Sierka, J. Sauer. Phys Rev Lett, 105 (2010), p. 146104.

16. F.J. Himpsel, P. Heimann, T.-C. Chiang, D.E. Eastman. Phys Rev B, 45 (1980), p. 1112.

17. G. Hollinger, F.J. Himpsel. Appl Phys Lett, 44 (1984), p. 93.

18. C.R.H. Bahl, D. Velázquez, K.K. Nielsen, K. Engelbrecht, K.B. Andersen, R. Bulatova, N. Pryds. Appl Phys Lett, 100 (2012), p. 121905.

19. W.M. Haynes. CRC Handbook of Chemistry and Physics. (Ninety third ed.)CRC Press (2012-2013). 

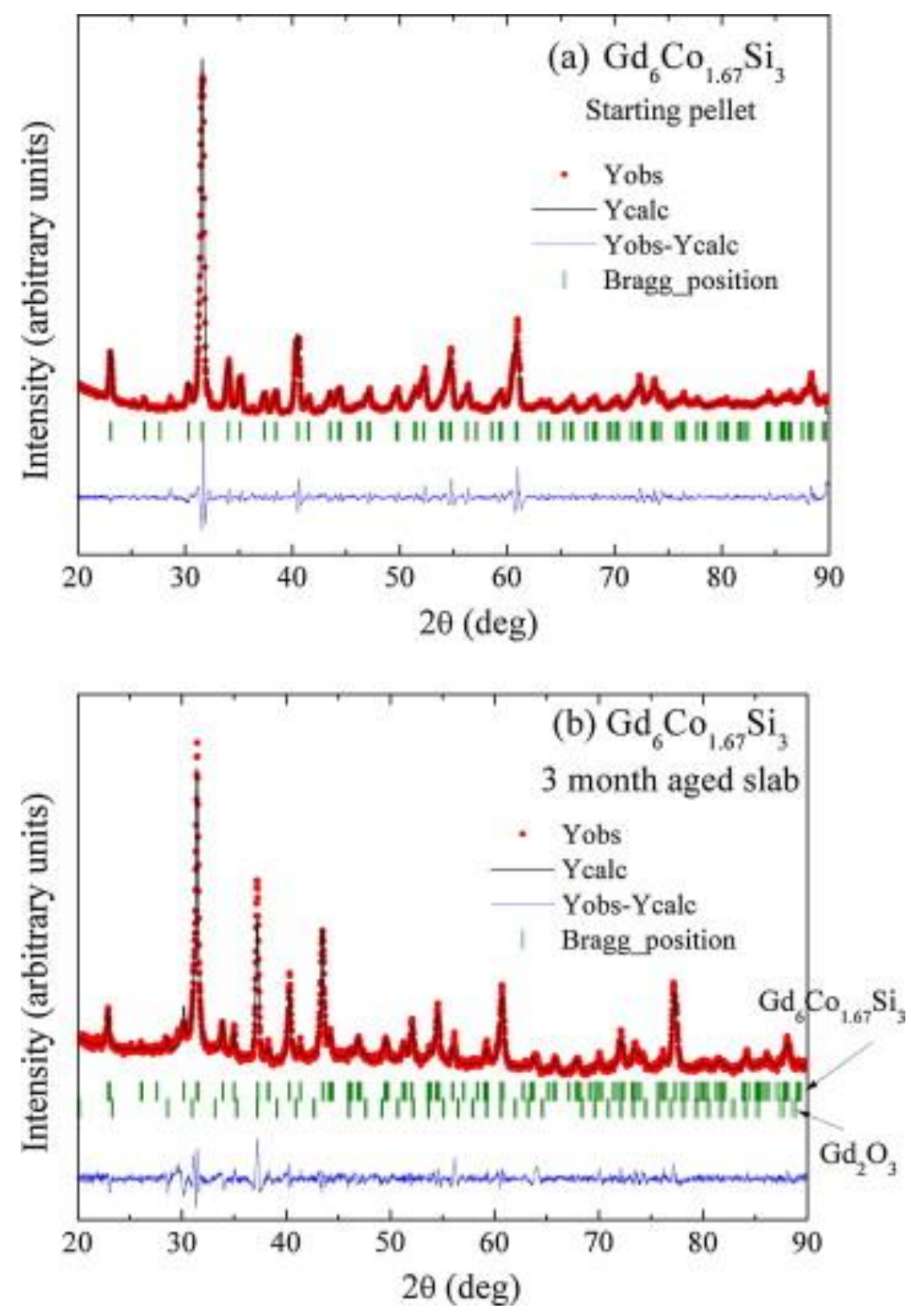

Fig. 1. X-ray diffraction profile matching for: (a) staring material, (b) 3 months aged. 

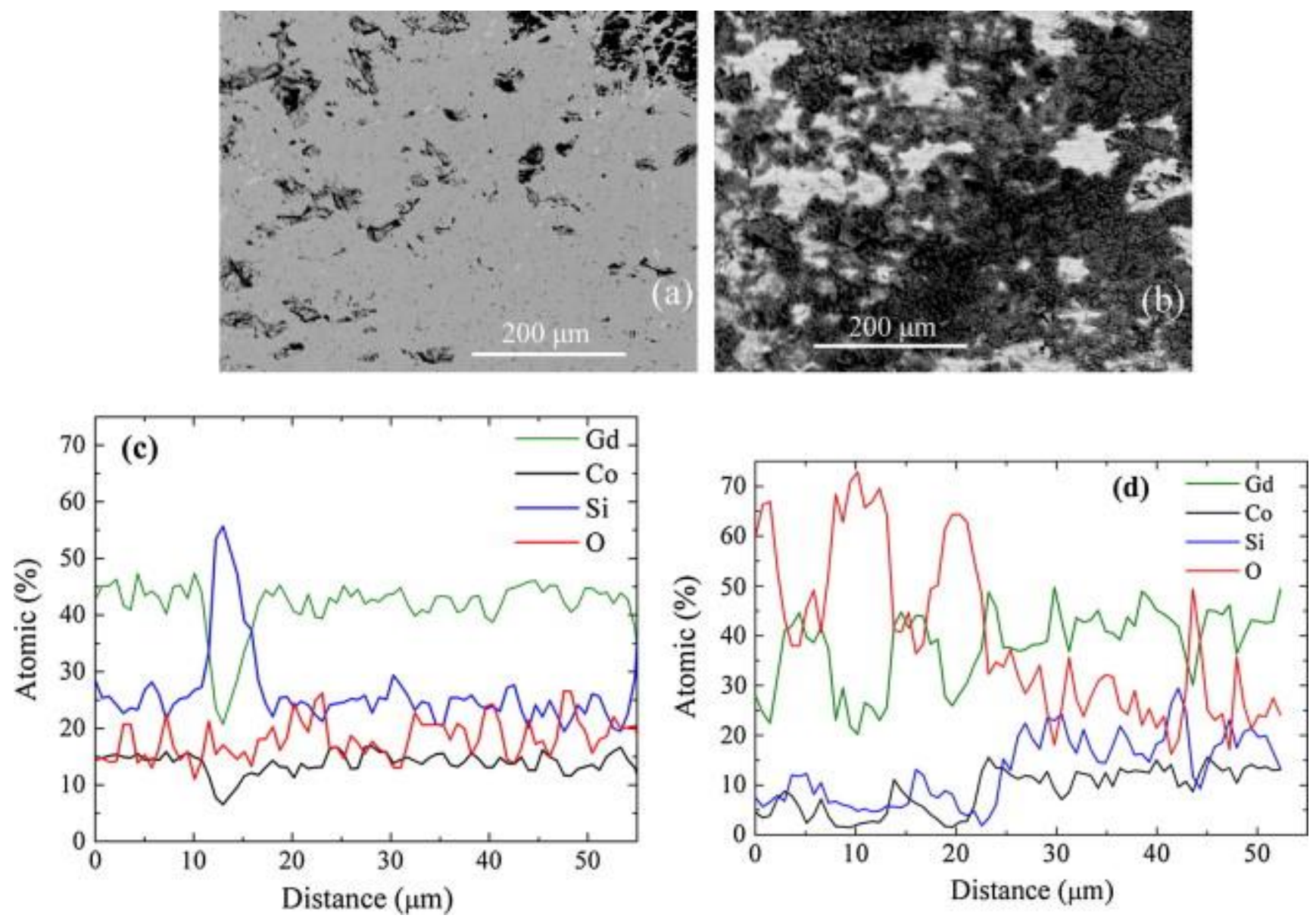

Fig. 2. Backscattered images of (a) starting and (b) 3 months aged samples obtained from EPMA. Elemental analysis along selected surface of the (c) starting and (d) 3 months aged samples. 

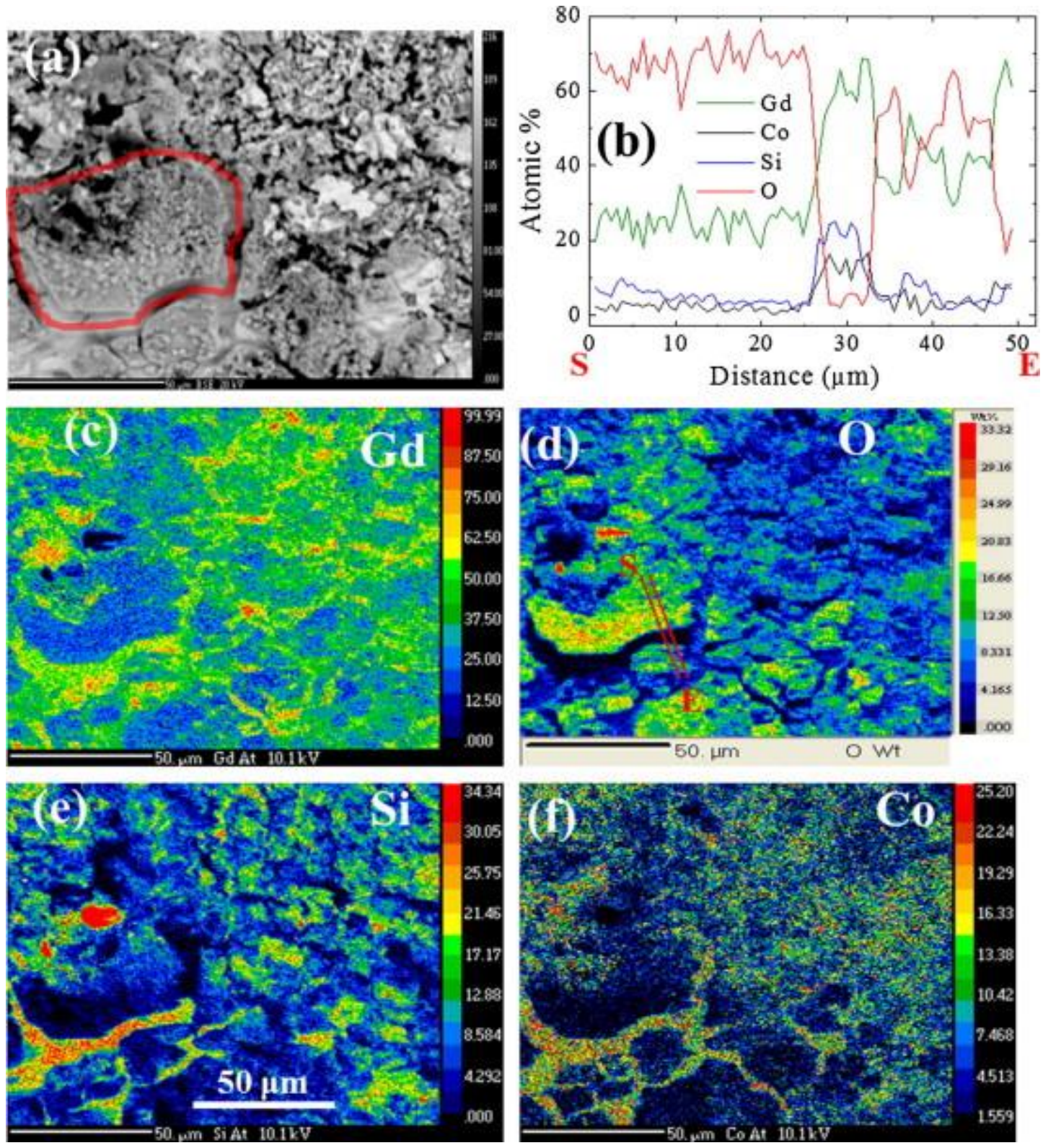

Fig. 3. (a) Backscattered image of 2 months aged sample slab. Elemental mapping of: (c) Gd-Gadolinium, (d) O-oxygen, (e) Si-Silicon and (f) Co-Cobalt area under study is same as that of (a). (b) selected area elemental analysis in terms of atomic percentage ( $\mathrm{S}$ refers to start point, $\mathrm{E}$ the end point). 

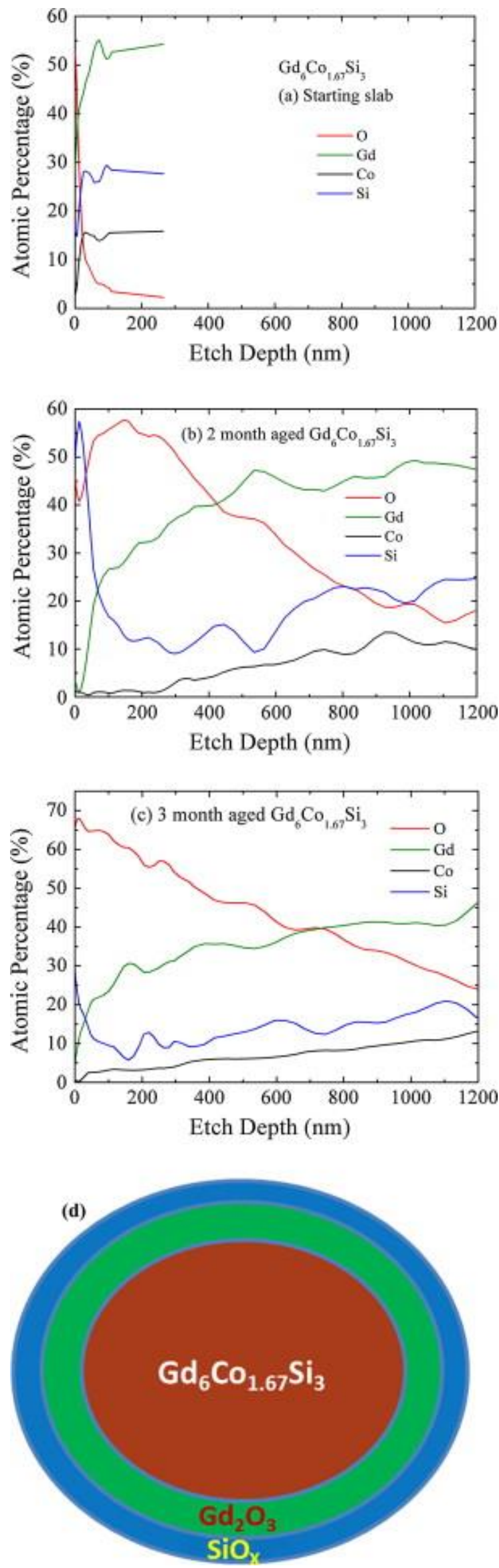
Fig. 4. Depth profile using Auger spectroscopy on: (a) starting, (b) 2 months aged and (c) 3 months aged material. (d) Proposed core-shell model of formation of oxide layer on surface of the material.

Table 1. Electrochemical reaction details for selected metals and metal oxides along with required potential $\left(E^{0}\right)$ [20].

Oxidation/reduction $\quad E^{0}(\mathrm{eV})$

\section{Electrochemical reaction}

$\mathrm{O}_{2} / \mathrm{OH}^{-} \mathrm{O} 2 / \mathrm{OH}-$

$\mathrm{Co}^{2+} / \mathrm{CoCo}+/ \mathrm{Co}$

$\mathrm{SiO} / \mathrm{SiSiO} / \mathrm{Si}$

$\mathrm{Si}^{i V} \mathrm{O}_{2} / \mathrm{SiOSilVO} 2 / \mathrm{SiO}$

$\mathrm{Si}^{I V} \mathrm{O}_{3}^{2-} / \mathrm{SiO}_{x} \mathrm{SilVO}_{2-}$

/SiOx

$\mathrm{Gd}^{3+} / \mathrm{GdGd} 3+/ \mathrm{Gd}$
$+0.401 \mathrm{O}_{2}+2 \mathrm{H}_{2} \mathrm{O}+4 \mathrm{e}^{-} \leftrightarrow 4 \mathrm{OH}^{-} \mathrm{O} 2+2 \mathrm{H}_{2} \mathrm{O}+4 \mathrm{e}-\leftrightarrow 4 \mathrm{OH}-$

$-0.28 \mathrm{Co}^{2+}+2 \mathrm{e}^{-} \leftrightarrow \mathrm{CoCo} 2++2 \mathrm{e}-\leftrightarrow \mathrm{Co}$

$-0.80 \mathrm{SiO}+\mathrm{e}^{-}+2 \mathrm{H}^{+} \leftrightarrow \mathrm{Si}+\mathrm{H}_{2} \mathrm{OSiO}+\mathrm{e}-+2 \mathrm{H}+\leftrightarrow \mathrm{Si}+\mathrm{H}_{2} \mathrm{O}$

$-0.90 \mathrm{SiO}_{2}+2 \mathrm{e}^{-}+2 \mathrm{H}^{+} \leftrightarrow \mathrm{SiO}+\mathrm{H}_{2} \mathrm{OSiO} 2+2 \mathrm{e}-+2 \mathrm{H}+\leftrightarrow \mathrm{SiO}+\mathrm{H}_{2} \mathrm{O}$

${ }_{-1.697} \mathrm{SiO}_{3}^{2-}+2 e^{-}+2 \mathrm{H}^{+} \leftrightarrow \mathrm{SiO}+2 \mathrm{H}_{2} \mathrm{O}_{\mathrm{SiO} 32-+2 \mathrm{e}-}$

$+2 \mathrm{H}+\leftrightarrow \mathrm{SiO}+2 \mathrm{H} 2 \mathrm{O}$

$-2.30 \mathrm{Gd} \Leftrightarrow \mathrm{Gd}^{3+}+3 \mathrm{e}^{-} \mathrm{Gd} \Leftrightarrow \mathrm{Gd} 3++3 \mathrm{e}^{-}$ 

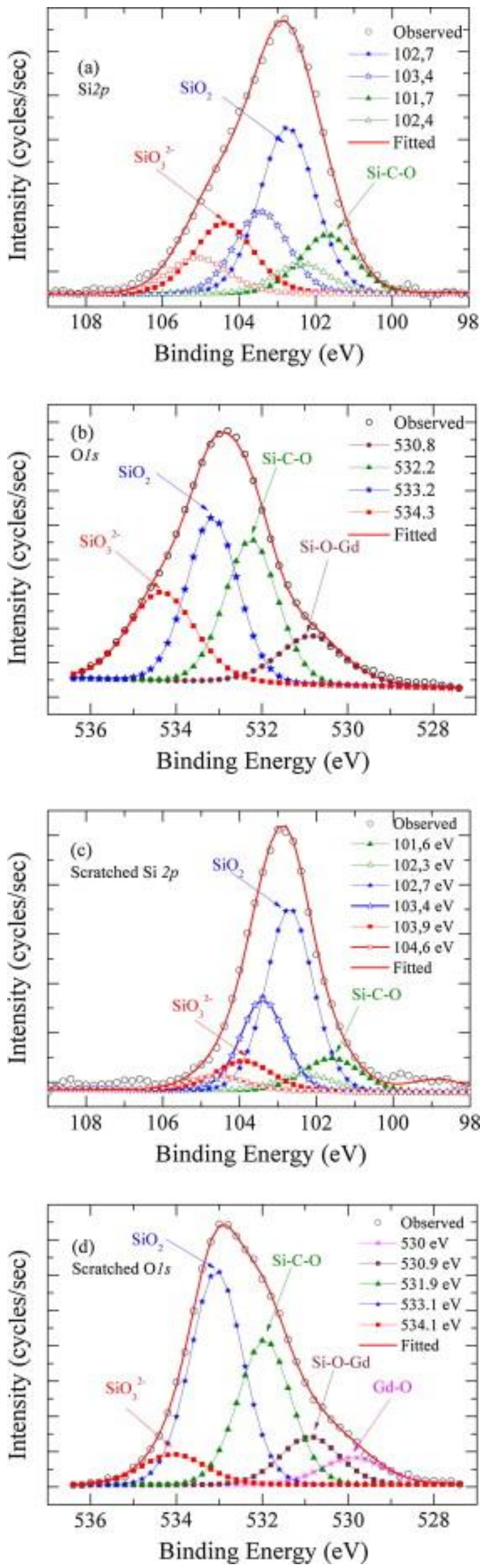
Fig. 5. X-ray photoelectron spectrum from surface of aged material: on surface (a) $\mathrm{Si} 2 p$ (b) $\mathrm{O} 1 s$; after scratch (c) $\mathrm{Si} 2 p(\mathrm{~d}) \mathrm{O} 1 \mathrm{~s}$.
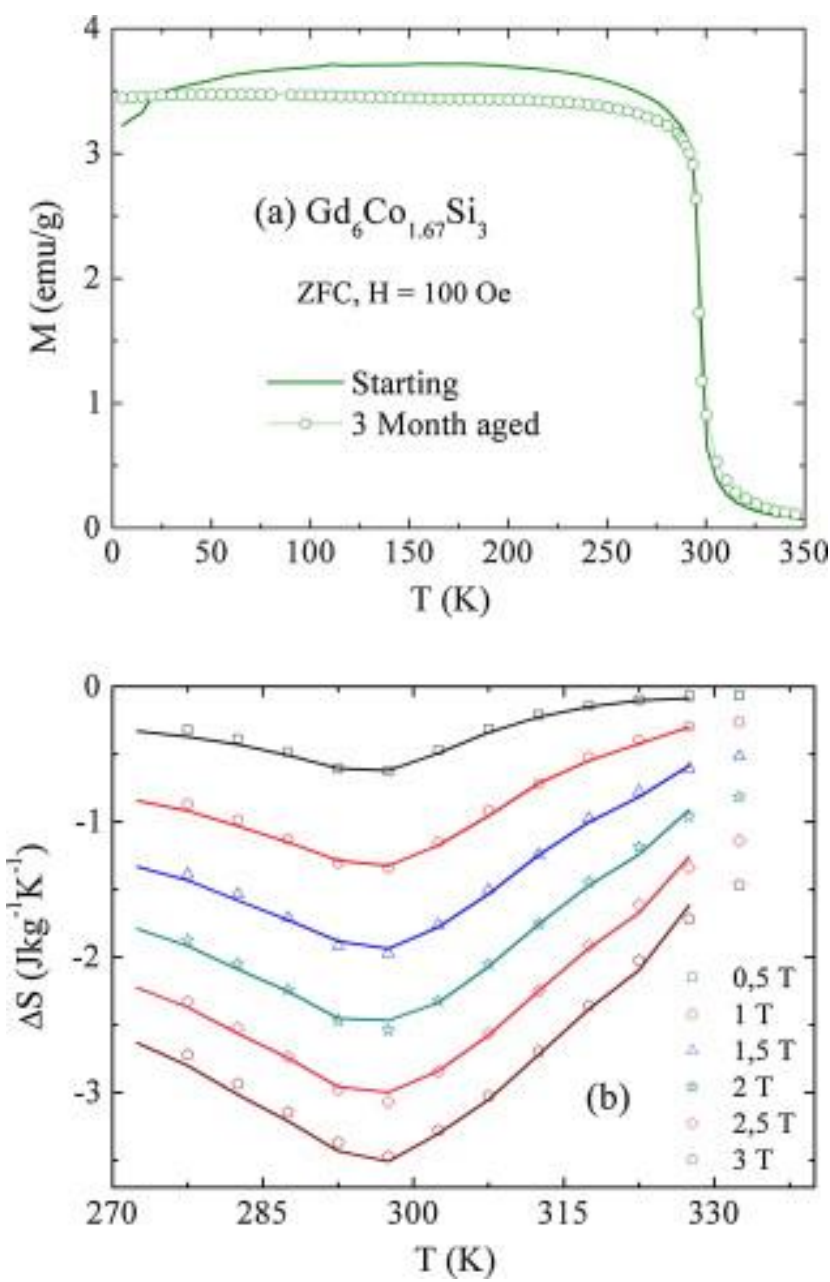

Fig. 6. (a) ZFC magnetization as function of temperature. (b) Entropy change. For both graphs solid line signifies starting and open symbols are for 3 months aged material. 